\title{
Модернизация конструкции аккумуляторов теплоты на основе твердых материалов для работы по ночному тарифу на электроэнергию
}

\author{
А. А. Климчук ${ }^{\bowtie}$, А. В. Лужанская, А. Н. Шраменко \\ Одесский национальный политехнический университет, пр. Шевченко, 1, Одесса, 65044, Украина \\ $\bowtie$ e-mail: ak@ctk.center
}

\begin{abstract}
Применение аккумуляторов теплоты на основе твердых веществ в системах теплоснабжения является актуальным при использовании двух- и трехзонного тарифа на электроэнергию. Основными преимуществами таких аккумуляторов теплоты являются простота конструкции и относительно мальй объем. Предложен алгоритм определения конструктивных параметров аккумулятора теплоты в зависимости от условий работы системы теплоснабжения. Разработаны рекомендачии по расположению нагревательных элементов в аккумулирующей насадке и выбору их количества, методика определения оптимальной толщчины аккумулирующего слоя, габаритов аккумулирующей насадки и удельного теплового потока на поверхность нагрева.
\end{abstract}

Ключевые слова: Аккумулятор теплоты; Нестационарная теплопроводность; Регулярный тепловой режим; Системы теплоснабжения

\section{Модернізація конструкції акумуляторів теплоти на основі твердих матеріалів для роботи за нічним тарифом на електроенергію}

\author{
О. А. Климчук, Г. В. Лужанська, О. М. Шраменко \\ Одеський національний політехнічний університет, пр. Шевченка, 1, Одеса, 65044, Україна
}

\begin{abstract}
Застосування акумулятора теплоти на основі твердих речовин в системах теплопостачання $\epsilon$ актуальним при використанні двох- і трьохзонного тарифу на електроенергію. Основними перевагами таких акумуляторів теплоти є простота конструкиї і відносно малий об'єм.. Запропоновано алгоритм визначення конструктивних параметрів акумулятора теплоти в залежності від умов роботи системи теплопостачання. Розроблено рекомендації щзодо розташування нагрівальних елементів в акумулюючій насадиі та вибору їх кількості, методику визначення оптимальної товщини акумулюючого шару, габаритів акумулюючої насадки і питомого теплового потоку на поверхню нагріву.
\end{abstract}

Ключові слова: Акумулятор теплоти; Нестаціонарна теплопровідність; Регулярний тепловий режим; Системи теплопостачання

DOI: http://dx.doi.org/10.15673/ret.v53i2.594

(C) The Author(s) 2017. This article is an open access publication

This work is licensed under the Creative Commons Attribution 4.0 International License (CC BY) http://creativecommons.org/licenses/by/4.0/

\section{1 Введение}

Развитие энергетики оказывает решающее влияние на состояние экономики в государстве и уровень жизни населения. Экономия первичных энергоресурсов и расширение возможности использования нетрадиционных источников энергии объективно обусловлены необходимостью. Для Украины эти проблемы имеют общегосударственное значение.

Для снижения потребности в строительстве генерирующих мощностей необходимо стимулировать не только сохранения электроэнергии, но и выравнивания графика нагрузки. Для этого требуется усиление дифференцированности тарифов на электроэнергию для конечного потребителя по времени суток и стимулирования снижения потребления электроэнергии в пиковое время за счет переноса потребления на другое время суток.

Кроме распространенных сейчас водяных аккумуляторов тепла, существуют также аккумуляторы на основе твердых материалов. Применение твердых материалов позволяет уменьшить размеры аккумулятора тепла за счет большей плотности и большого диапазона рабочих температур [1].

В системах теплоснабжения зданий целесообразно использование аккумуляторов теплоты объемного типа на основе жидких и твердых материалов. Среди жидких аккумулирующих материалов чаще всего используют 
воду благодаря ее теплофизическим свойствам и доступности. Использование твердых материалов позволяет в значительной степени уменьшить объем аккумулятора теплоты за счет восоких рабочих температур и простоты конструкции, а также при небольшой мощности аккумулятора появляется возможность использовать его непосредственно в отапливаемом помещении [2].

\section{2 Моделирование процесса зарядки аккуму- лятора теплоты}

Для описания распределения температуры в теле был предложен метод, который заключается в том, что весь процесс нагрева и охлаждения тела разбивается на две стадии. Первая стадия соответствует проникновению тепла в толщину тела (так называемый инерционный период), вторая - изменении температуры тела по всему объему одновременно.

В обоих случаях действительная кривая распределения температуры в теле заменяется на параболу $n$-го порядка. Вид уравнения параболы не зависит от направления теплового потока, то есть от того, нагревается или охлаждается.

Установлено, что в соответствии с принципом стабильности теплового потока, форма поверхности нагрева влияет на распределения температуры в теле только вблизи этой поверхности, а на достаточном расстоянии от поверхности форма температурного поля будет зависеть от направления распространения теплового потока в теле [3]. То есть, если тело нагревается изнутри через квадратную полость, то на определенном расстоянии от нагревателя температурное поле будет цилиндрическим, так как имеет место радиальное распространение теплоты (рисунок 1).

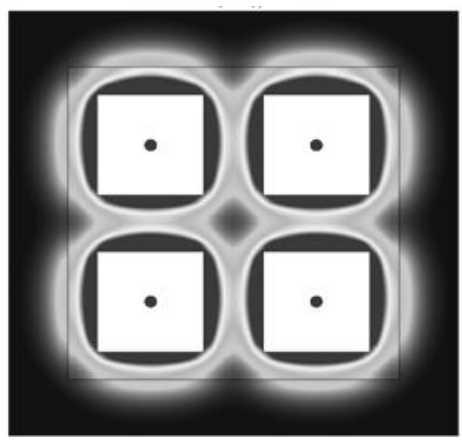

Рисунок 1 - Температурное поле 6 твердом теле при нагреве изнутри

В соответствии с этим для описания поля температур в цилиндрическом теле при нагреве постоянным тепловым потоком изнутри используется уравнение:

$$
t=t_{0}+\Delta t \cdot\left(1-\frac{x}{X}\right)^{n}
$$

где $X$ - толщина прогретого слоя материала, м; $x$ координата точки, в которой определяется температура; $\Delta t=t_{n}-t_{0}-$ перепад температур по толщине тела, ${ }^{\circ} \mathrm{C}$; $t_{0}$ - начальная температура, ${ }^{\circ} \mathrm{C} ; t_{n}$ - температура на поверхности тела, ${ }^{\circ} \mathrm{C}$.
Величина перепада температур определяется следующим образом:

$$
\Delta t=\frac{q_{n o в} \cdot X}{k \cdot \lambda}
$$

где $q_{\text {пов }}$ - тепловой поток на поверхность тела, Вт/м² $k$ - коэффициент усреднения плотности теплового потока; $\lambda$ - теплопроводность материала, $B m /(M \cdot K)$.

В результате моделирования была найдена зависимость для определения коэффициента усреднения теплового потока $k$ для случая нагрева изнутри при граничных условиях второго рода.

В интервале отношения наружного радиуса к внутреннему $4 \leq R / r<30$ зависимость $k=f(R / r)$ имеет вид прямой линии, которая описывается уравнением [4] $k=0.262 \cdot R / r+2$.

Проведено экспериментальное исследование процесса зарядки и разрядки аккумулятора теплоты с помощью экспериментального стенда (рисунки 2,3,4).

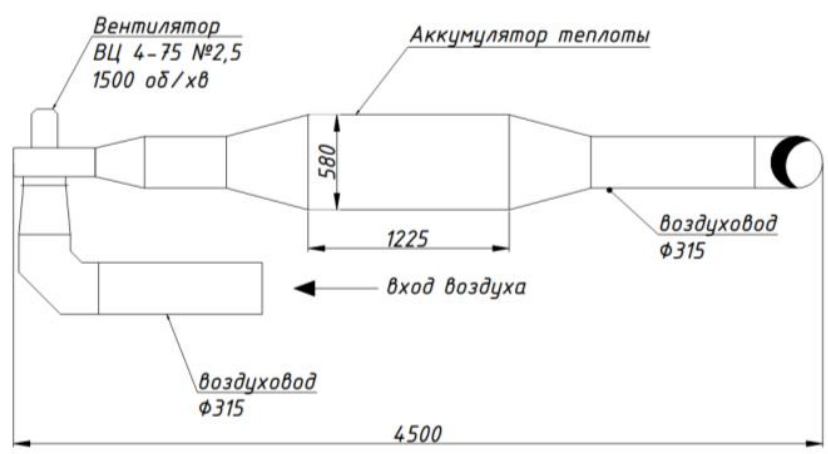

Рисунок 2 - Схема експериментального стенда

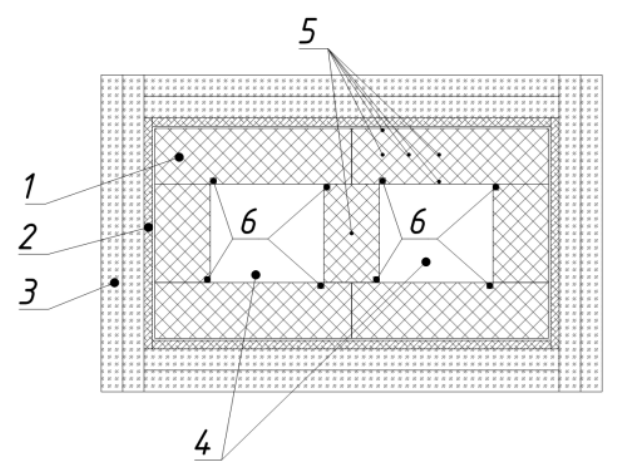

Рисунок 3 - Поперечное сечение аккумулятора теплоты:

1 - шамотный кирпич; 2 - магнезитовая плита; 3 минеральная вата; 4 - канал для прохода воздуха; 5 места расположения термопар; 6 - нагревательные элементыл

Рассмотрены следующие режимы зарядки и разрядки аккумулятора теплоты:

1) Зарядка с подключенными воздуховодами. Воздуховоды ни были перекрыты, поэтому при этом через каналы аккумулирующей насадки естественным путем проходил воздух.

2) Зарядка с отключенными воздуховодами. Каналы в аккумулирующей насадке были закрыты теплоизоли- 
рующим материалом для предотвращения возникновения естественной конвекции.

3) Зарядка с включенным вентилятором. Одновременно происходили и нагрев аккумулирующей насадки, и отдача теплоты от насадки к воздуху

4) Разрядка с отключенными воздуховодами. Каналы в аккумулирующей насадке были закрыты теплоизолирующим материалом для предотвращения возникновения естественной конвекции.

5) Разрядка с включенным вентилятором.

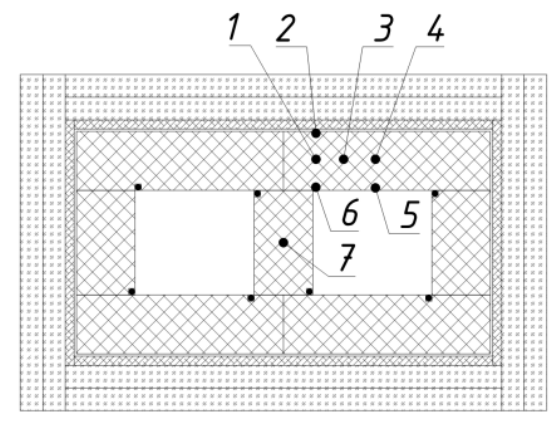

\section{Рисунок 4 - Расположение термопар} в аккумулирующей материале

В результате эксперимента были получены данные о распределении и характере изменения температур в различных точках аккумулирующей насадки.

Анализ полученных данных показал, что характер изменения температуры аккумулирующего материала при нагреве отличается от линейного (что должно быть из условия неизменности теплового потока) за счет тепловых потерь в окружающее пространство. Поэтому для расчета времени нагрева материала надо учитывать влияние конвективного теплообмена аккумулятора теплоты с окружающей средой. В нашем случае теплота аккумуляции теряется через теплоизолирующий слой и путем конвективного теплообмена при естественной циркуляции воздуха через аккумулирующую насадку.

На основе экспериментальных данных установлено:

1) закон изменения логарифма избыточной температуры при нагревании и охлажденные материала является линейным;

2) процесс охлаждения и нагрева аккумулирующей насадки можно розделить во времени на две стадии: стадию неупорядоченного (иррегулярного) процесса и стадию регулярного режима.

Эти данные позволяют использовать для описания процессов накопления и отдачи тепла теорию регулярного теплового режима Кондратьева.

\section{3 Выбор оптимальных конструктивных пара- метров}

Констукция аккумулятора теплоты должна обеспечивать:

1) максимальную скорость достижения среднемассовой температуры аккумулирующего материала до необходимого значения при зарядке;

2) максимальное использование аккумулирующего объема;
3) минимальный размер аккумулятора теплоты;

4) минимальные температурные напряжения в аккумулирующем материале.

Анализ данных, полученных на основе теоретического расчета процесса нагрева цилиндрического тела (рисунок 5) постоянным тепловым потоком изнутри, показал, что при нагревании теплота неравномерно распределяется по толщине цилиндра (рисунок 6).

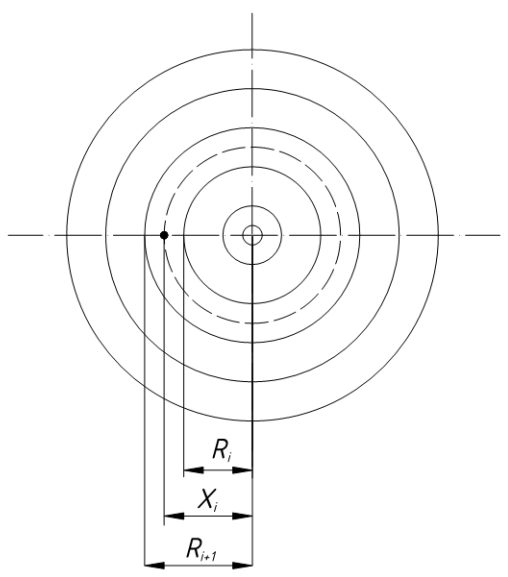

Рисунок 5 - Расчетная схема для определения
равномерности прогрева

Рассчитывалась количество теплоты, аккумулированная в определенной области цилиндрического тела при нагревании до различных температур:

$$
Q_{i}=m_{i} \cdot c \cdot \Delta t=\pi \cdot\left(R_{i+1}^{2}-R_{i}^{2}\right) \cdot l \cdot \rho \cdot\left(t_{X_{1}}-t_{0}\right),
$$

где $t_{0}$ - начальная температура, ${ }^{\circ} \mathrm{C} ; t_{X_{1}}-$ температура в точке $X_{l},{ }^{\circ} \mathrm{C} ; l$ - длина цилиндра, м.

\section{$\mathbf{Q} / \mathbf{m}, \mathbf{к Д ж / к г ~}$}

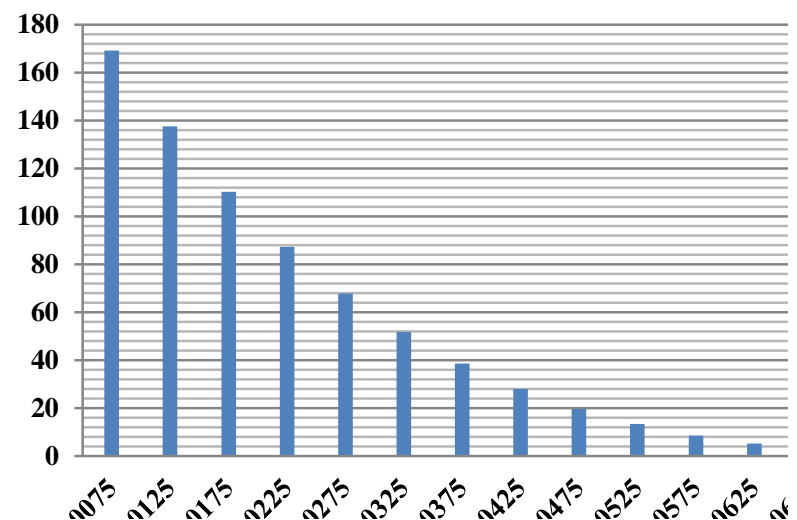

Рисунок 6 - Распределение теплоты в цилиндре в коние инериионного периода

Наибольшая неравномерность наблюдается в конце инерционного периода, когда внутренняя половина 
цилиндра содержит в себе 88,2\% аккумулированной теплоты, при этом масса этой части составляет 27,5\% от общей массы тела.

Эта неравномерность уменьшается с течением времени и через достаточно длинный отрезок $\left(F o \gg F O^{\prime}\right)$ практически исчезает. Поэтому для максимального использования аккумулирующего объема необходимо, чтобы продолжительность нагрева значительно превышала продолжительность инерционного периода.

На основе анализа теоретических данных и результатов компьютерного моделирования разработаны рекомендации по выбору эффективного расстояния между нагревательными элементами. Для того, чтобы не было зон, которые практически не прогреваются (рисунок 7а) в связи с особенностями распространения теплоты при нагревании изнутри, необходимо, чтобы расстояние между нагревательными элементами была не более чем два эквивалентных радиуса (рисунок 7б), определяемых как:

$$
R_{e}=\sqrt{\frac{F_{c e u}}{\pi \cdot n}+r^{2}}
$$

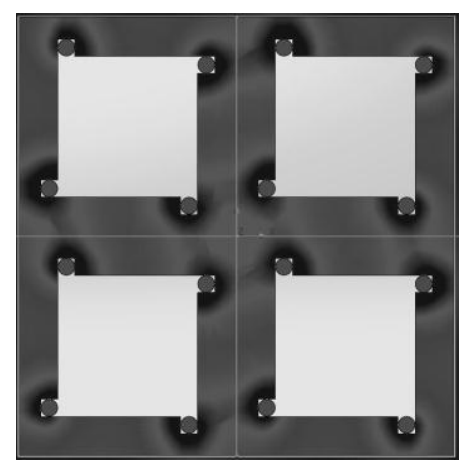

a)

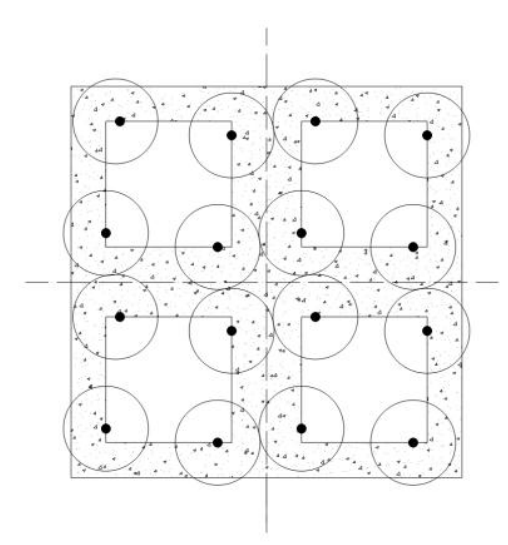

б)

Рисунок 7 - Распределение теплоты в насадке аккумулятора: а) температурное поле при нагревании; б) изображение эквивалентных циилиндров, радиусы которых получены расчетным путем.

На основе анализа влияющих факторов разработан следующий алгоритм определения конструктивных параметров аккумулятора теплоты:

1) Определение расчетной тепловой нагрузки;

2) Определение необходимой продолжительности периодов зарядки и разрядки. При использовании двух и трехзонного тарифа на электроэнергию продолжительность зарядки зависит от продолжительности ночного периода. Продолжительность разрядки может определяться, например, режимом работы помещений (если рассматриваются общественные и административные здания, в которых допускается в нерабочее период поддерживать «дежурную» температуру внутреннего воздуха);

3) Определение массы аккумулирующего материала. Определяющими факторами в данном случае будут выступать тепловая нагрузка, период работы системы отопления и диапазон рабочих температур аккумулирующего теплоту материала.

4) С учетом количества теплоты, которое нужно аккумулировать, и время, за которое это необходимо сделать, осуществляется определение суммарной тепловой мощности нагревательных элементов аккумулятора теплоты;

5) Исходя из продолжительности периода нагрева и допустимых температур аккумулирующего материала и нагревательных элементов рассчитывается количество нагревателей, используя методику определения эквивалентного радиуса нагрева;

6) В зависимости от технических возможностей сборки аккумулятора теплоты выбирается способ расположения нагревательных элементов в насадке;

7) После расчета эквивалентного радиуса прогрева для выбранного количества нагревательных элементов определяется оптимальное расстояние между ними;

8) В зависимости от схемы расположения нагревательных элементов, расчетного теплового потока на поверхность и теплофизических свойств определяется толщина аккумулирующего слоя;

9) Определение размеров каналов для прохода воздуха и их количества в зависимости от тепловой мощности аккумулятора теплоты.

Предложенный алгоритм позволяет определить все необходимые конструктивные параметры аккумулирующей насадки, опираясь на режим работы системы отопления.

\section{4 Выводы}

1. Основными параметрами аккумулятора теплоты, влияющими на эффективность его работы, является толщина аккумулирующего материала, удельный тепловой поток на поверхность и перепад температур по толщине материала. Однако, современные аналитические методы расчета нестационарной теплопроводности не позволяют полноценно использовать их для анализа теплообмена в аккумулирующей насадке. Для этих целей целесообразно применять приближенные инженерные методики.

2. Разработана методика определения оптимальных конструктивных параметров и режима работы аккумулятора теплоты в зависимости от отопительной нагрузки. На основе данных, полученных с помощью разработанной методики расчета нагрева твердых тел изнутри постоянным тепловым потоком, даны рекомендации по оптимизации продолжительности нагрева аккумулирующей насадки, выбору количества нагревательных элементов и их расположения, расчету толщины аккумулирующего слоя. 


\section{Литература}

1. Климчук А. А., Шраменко А. Н. Анализ способов применения различных теплоаккумулирующих материалов // Збірник наукових праць X всеукраїнської науково-технічної конференції студентів і аспірантів «Еколого-енергетичні проблеми початку XXI століття», Одеса 2010. - C. 81-83.

2. Титар С.С., Климчук О.А., Шраменко О.М. Застосування акумуляторів тепла на основі твердих матеріалів в системах теплопостачання з використанням електроенергії // Науковий журнал «Вісник вінницького політехнічного інституту», вип. 4. - Вінниця, 2012. C. 112-115.
3. Климчук О.А., Шраменко О.М. Інтенсифікація процесу розрядки акумулятора тепла на основі твердих матеріалів // Збірник статей VIII Всеукраїнської науково-практичної конференції «Охорона навколишнього середовища промислових регіонів як умова сталого розвитку України», Запоріжжя 2012. - С. 120-122.

4. Шраменко О.М. Удосконалення конструкції та режимів роботи акумуляторів теплоти на основі твердих матеріалів: дис. канд. техн. наук: 05.14.06 / Шраменко Олдександр Миколайович. - Одесса, 2016. - 148 с.

Отримана в редакції 24.02.2017, прийнята до друку 25.04.2017

\title{
Construction Modernization of Heat Accumulators Based on Solid Materials for Electricity Night Tariffs Operation
}

\author{
A. A. Klymchuk ${ }^{\bowtie}$, G. V. Luzhanska, A. N. Shramenko \\ Odessa national polytechnic university, 1 Shevchenko av., Odessa, 65044, Ukraine \\ $\triangle$ e-mail: ak@ctk.center
}

The use of heat accumulators based on solids in heat supply systems is relevant when using a two-and three-zone electricity tariff. The main advantages of such heat accumulators are simplicity of design and relatively small volume. The main parameters of the heat accumulator, affecting the efficiency of its operation, is the thickness of the accumulating material, the specific heat flux to the surface, and the temperature drop across the thickness of the material. Existing analytical methods for calculating the non-stationary thermal conductivity are practically not applicable for describing the processes of charging and discharging the battery.Based on computer simulation data, the method of calculating solid bodies under boundary conditions of the second kind has been further developed. The process of charging and discharging the heat accumulator with the help of an experimental stand was carried out. The processes of charging and discharging the heat battery under various operating conditions are investigated. It has been proved experimentally that it is permissible to use the theory of a regular thermal regime to describe the process of heating and cooling an accumulating headpiece. On the basis of the data obtained as a result of the experiment, the theory of thermal regular regime was further developed in the part of calculating the cooling and heating of bodies in convective heat exchange in channels and internal sources of heat. An algorithm for determining the design parameters of the heat accumulator in dependence of the operating conditions of the heat supply system is proposed. It is shown that to maximize the use of the storage volume it is necessary that the heating duration significantly exceed the duration of the inertial period. The recommendations on the location of heating elements in the accumulating nozzle and the choice of their number, the procedure for determining the optimum thickness of the accumulating layer, the dimensions of the accumulating nozzle and the specific heat flux to the heating surface are developed.

Keywords: Battery Heat; Unsteady Heat Conduction; Regular Thermal Mode; Heating System

\section{References}

1. Klymchuk, A.A., Shramenko, A.N. (2010) Analiz sposobov primeneniia razlichnykh teploakkumuliruiushchikh materialov. Zbirnyk naukovykh prats $\mathrm{X}$ vseukrayins'koi naukovo-tekhnichnoi konferentsii studentiv $\mathrm{i}$ aspirantiv «Ekoloho-enerhetychni problemy pochatku XXI stolittia», Odesa 2010, 81-83 (in Russian)

2. Tytar, S.S., Klymchuk, O.A., Shramenko, O.M. (2012) Zastosuvannia akumuliatoriv tepla na osnovi tverdykh materialiv $\mathrm{V}$ systemakh teplopostachannya $\mathrm{Z}$ vykorystanniam elektroenerhii. Visnyk vinnytskoho politekhnichnoho instytutu, iss. 4, Vinnytsia, 112-115 (in Ukrainian)

3. Klymchuk, O.A., Shramenko, O.M. (2012) Intensyfikatsiia protsesu rozryadky akumuliatora tepla na osnovi tverdykh materialiv. Zbirnyk statey VIII Vseukrayins'koi naukovo-praktychnoi konferentsii «Okhorona navkolyshnoho seredovyshcha promyslovykh rehioniv iak umova staloho rozvytku Ukrayiny», Zaporizhzhya, 120-122 (in Ukrainian)

4. Shramenko, O.M. (2016) Udoskonalennia konstruktsii ta rezhymiv roboty akumuliatoriv teploty na osnovi tverdykh materialiv: dys. kand. tekhn. nauk: 05.14.06. Odessa, 2016. - 148 p.

Received 24 February 2017 Approved 25 April 2017 Available in Internet 29 May 2017 